\title{
5-Hydroxytryptamine levels and platelet aggregation responses in subjects with acute migraine headache
}

\author{
BARBARA P. HILTON AND J. N. CUMINGS \\ From the Institute of Neurology, National Hospital, Queen Square, London
}

SUMMARY Blood 5-hydroxytryptamine levels were reduced during migraine attacks in patients who had not taken any drugs but the aggregation responses to 5-hydroxytryptamine of the blood platelets from these patients were similar to responses of platelets from migrainous subjects between attacks. This confirms earlier findings that a permanent difference exists in the behaviour of platelets from migrainous subjects. Blood 5-hydroxytryptamine levels were reduced during migraine attacks in patients who had taken ergotamine. The aggregation responses of platelets taken from migrainous patients on ergotamine both during and between attacks were inhibited, which is in agreement with results previously found for aggregation responses following the in vitro pre-incubation of control platelets with ergotamine. Blood 5-hydroxytryptamine levels were maintained during migraine attacks in patients who had taken analgesics and there was no reduction in the aggregation responses of their platelets.

Blood was taken from migrainous patients during acute migraine headache for estimation of 5-hydroxytryptamine (5-HT) and platelet aggregation studies. Results obtained for patients who had not taken drugs were compared with those for patients who had taken ergotamine or analgesics.

Platelet aggregation responses to 5-HT depend on the availability of 5-HT uptake sites on the platelet membrane (Baumgartner and Born, 1968). When the uptake site is empty, aggregation can occur but if the uptake site is already occupied by a 5-HT molecule, aggregation cannot take place. A difference has already been noted between the aggregation responses to 5-HT of platelets from migrainous patients without headache and those of normal control subjects (Hilton and Cumings, 1971). It was anticipated that a further difference might occur during migraine headache, since plasma 5-HT falls during a migraine attack (Curran, Hinterberger, and Lance, 1965) and in control subjects the platelet aggregation response to 5-HT is inversely proportional to the blood 5-HT content (Hilton and Cumings, 1971).

\section{METHODS}

Blood was collected from patients with classical and common migraine during and between acute migraine attacks. Migrainous subjects were included in the between headache group if they had not suffered an acute migraine attack for three days. Patients were questioned carefully about any drugs or medication they had taken within the previous three days and were divided into groups: (1) patients who had not taken any drugs; (2) patients who had taken analgesics; (3) patients who had taken ergotamine.

'Analgesics' refer to preparations comprising, Veganin, Anadin, Panadol, Aspirin, and Hedex, irrespective of dose level.

Ergotamine was taken in several different forms:

a. Patients without headache took $1-2 \times 10^{-3} \mathrm{~g}$ daily, as Migril, Cafergot suppositories, or Bellergal Retard.

b. Patients with migraine headache had been given an intramuscular injection of Femergin, $\frac{1}{2}$ to one hour previously, containing $0.25-0.50 \times 10^{-3} \mathrm{~g}$ ergotamine.

c. Patients with migraine headache had taken $2-4 \times 10^{-3}$ g ergotamine within the previous six hours, as Cafergot tablets, Cafergot Q, Cafergot suppositories, or Migril.

Blood for 5-HT estimation was collected into heparin and deep-frozen $\left(-20^{\circ} \mathrm{C}\right)$ immediately. The estimation was carried out using the method of Ashcroft, Crawford, Binns, and MacDougall (1964) and the 5-HT content was expressed per $\mathrm{cm}^{3}$ blood, 
corrected to a theoretical platelet count of 250,000 per $\mathrm{mm}^{3}$.

Platelet aggregation responses to 5-HT were measured as previously described (Hilton and Cumings, 1971) using an EEL platelet aggregation meter linked to a Honeywell chart recorder, where aggregation without pre-incubation was expressed as the rate of aggregation $(\mathrm{R} \mathrm{cm} / \mathrm{min})$ shown on the chart paper; after pre-incubation the rate of aggregation $\left(R_{1} \mathrm{~cm} / \mathrm{min}\right)$ was expressed relative to the response without pre-incubation as $R_{\mathbf{t}} / \mathbf{R}$. Values of $\mathbf{R}$ and $\mathbf{R}_{\mathbf{1}}$ were corrected to a platelet count of 250,000 per $\mathrm{mm}^{3}$.

Aggregation was induced and pre-incubations performed using 5-HT (serotonin creatinine sulphate, B.D.H.) $5 \times 10^{-8} \mathrm{~mol}$ in $0.1 \mathrm{~cm}^{3}$.

\section{RESULTS}

BLOOD 5-HYDROXYTRYPTAMINE The blood 5-HT levels for migrainous patients with acute headache, migrainous patients without headache and control subjects, can be seen in Table 1. However, the headache group in this table does not distinguish between those patients who had and had not taken drugs.

TABLE 1

BLOOD 5-HT LEVELS IN ALL SUBJECTS WITH AND WITHOUT ACUTE MIGRAINE HEADACHE

\begin{tabular}{lccc}
\hline Subjects & Headache & $\begin{array}{c}\text { Mean } 5-H T \\
\left(10^{-9} \mathrm{~g} / \mathrm{cm}^{3} \text { blood }\right) \\
\pm S E M\end{array}$ & $\begin{array}{c}\text { Number of } \\
\text { patients }\end{array}$ \\
\hline Control & - & $158 \cdot 4 \pm 2 \cdot 8^{*}$ & 142 \\
Migraine & - & $145 \cdot 8 \pm 13 \cdot 0$ & 20 \\
Migraine & + & $133.7 \pm 11 \cdot 2$ & 54 \\
\hline
\end{tabular}

Some patients with headache were on drugs (fuller details in Table 2) but neither of the other two groups had taken drugs.

* See Hilton and Cumings (1971).

When the blood 5-HT level of the headache group is subdivided according to the drugs taken by the patients, the mean 5-HT level of the 12 patients who had not taken drugs and the mean level of those patients on a large dose of ergotamine are significantly less than for the control group of normal subjects (Table 2). However, there is no significant difference between the control group and those subjects on a small ergotamine dose but this latter mean is high due
TABLE 2

BLOOD 5-HT LEVELS IN 54 SUBJECTS WITH ACUTE MIGRAINE HEADACHE (INCLUDED IN TABLE 1), WITH AND WITHOUT DRUGS

\begin{tabular}{|c|c|c|}
\hline & $\begin{array}{c}5-\mathrm{HT} \\
\left(10^{-9} \mathrm{~g} / \mathrm{cm}^{3} \text { blood }\right) \\
\pm S E M\end{array}$ & $\begin{array}{c}P \\
\text { (measured against } \\
\text { control normal } \\
\text { group) }\end{array}$ \\
\hline Control normal group & $\begin{array}{c}158 \cdot 4 \pm 2 \cdot 8^{*} \\
(142)\end{array}$ & \\
\hline No drugs & $\begin{array}{c}93 \cdot 4 \pm 8 \cdot 4 \\
(12)\end{array}$ & $<0.001$ \\
\hline Analgesics & $\begin{array}{c}181 \cdot 5 \pm 17 \cdot 3 \\
(13)\end{array}$ & NS \\
\hline $\begin{array}{l}\text { Ergotamine } \\
\left(0.25-0.50 \times 10^{-3} \mathrm{~g}\right) \\
\text { Ergotamine } \\
\left(2-4 \times 10^{-3} \mathrm{~g}\right)\end{array}$ & $\begin{array}{c}152 \cdot 1 \pm 26 \cdot 3 \\
(17) \\
96 \cdot 2 \pm 15 \cdot 5 \\
(12)\end{array}$ & $\begin{array}{c}\text { NS } \\
<0.001\end{array}$ \\
\hline
\end{tabular}

The number of subjects in each group is shown in parentheses. * See Hilton and Cumings (1971).

to raised 5-HT levels of three individuals (Figure). The headache group who had taken analgesicso had a raised mean 5-HT level.

There is no significant difference between the blood 5-HT level of a group of headache-free patients who had taken analgesics, comparedo with patients who had not taken drugs, as can seen in Table 3. However, patients without $\square$ headache who had taken ergotamine had lower mean 5-HT level.

Blood from headache patients who had nồt $\overrightarrow{0}$ taken drugs was collected from 0.5 to $7 \cdot 0$ hoưrs N of the onset of the symptoms and within these time limits no apparent trend in 5-HT level with increasing time was seen (Figure). Blood from patients who had taken analgesics was collected from two to 21 hours of the onset, ergotamine $\mathbb{D}$

TABLE 3

BLOOD 5-HT LEVELS OF MIGRAINOUS PATIENTS WITHOUT HEADACHE FOR THREE DAYS OR MORE

\begin{tabular}{|c|c|c|}
\hline & $\begin{array}{c}5-H T \\
\left(10^{-9} \mathrm{~g} / \mathrm{cm}^{3} \text { blood }\right) \\
\pm S E M\end{array}$ & $\begin{array}{c}P \\
\text { (measured against } \\
\text { no drugs group) }\end{array}$ \\
\hline No drugs & $\begin{array}{c}145 \cdot 8 \pm 13 \cdot 0 \\
(20)\end{array}$ & \\
\hline Ergotamine & $\begin{array}{c}107 \cdot 5 \pm 11 \cdot 0 \\
\text { (11) }\end{array}$ & $<0.05$ \\
\hline Analgesics & $\begin{array}{c}143 \cdot 8 \pm 15 \cdot 7 \\
(12)\end{array}$ & NS \\
\hline
\end{tabular}

The number of subjects in each group is shown in parentheses. 


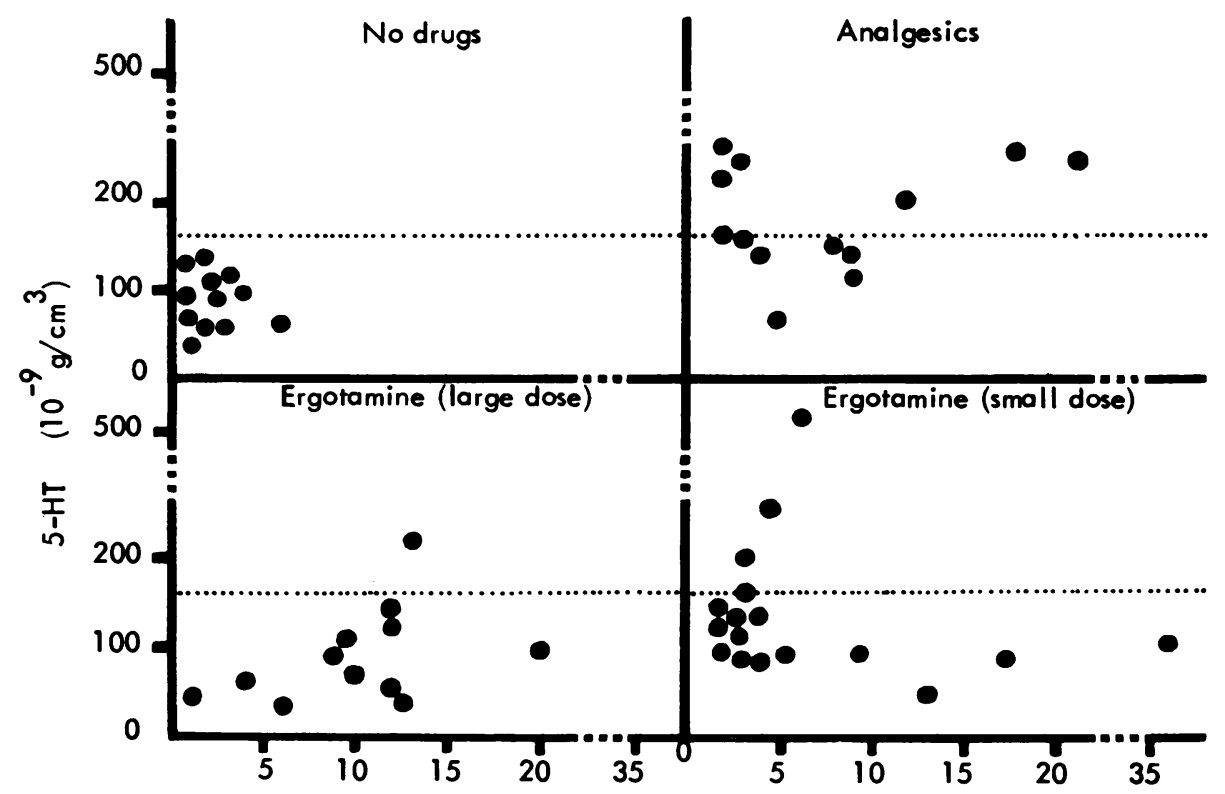

Hours since onset of migraine attack

FIGURE Blood 5-HT level: hours since onset of migraine attack.

(small dose) two to 36 hours, and ergotamine (large dose) one to 20 hours and these showed no special relationship between 5-HT and headache. An average normal blood 5-HT level has been inserted on the Figure and this value $(158 \times$ $10^{-9} \mathrm{~g}$ was obtained previously for 142 control subjects (see Hilton and Cumings, 1971).

PLATELET AGGREgATION RESPONSES The aggregation responses without pre-incubation $(R)$ of control subjects and migrainous patients with and without headache are not significantly different, as can be seen in Table 4. After one minute's pre-incubation with 5-HT the responses of migrainous subjects with and without headache are not significantly different from each other but are different from the responses of control subjects at the levels $P<0.05$ and $P<0.001$, respectively. After ergotamine ingestion the responses were inhibited significantly (Table 5), although this effect was less pronounced with the small ergotamine doses.

TABLE 4

5-HT INDUCED PLATELET AGGREGATION IN PATIENTS WITH ACUTE MIGRAINE HEADACHE

\begin{tabular}{|c|c|c|c|c|c|c|}
\hline Subjects & Headache & Drugs & $\begin{array}{c}R \\
\underset{(\mathrm{cm} / \mathrm{min})}{ \pm S E M}\end{array}$ & $P$ & $\begin{array}{c}R_{i} / R \\
\pm S E M\end{array}$ & $P$ \\
\hline & - & - & $\begin{array}{c}1 \cdot 21 \pm 0.08^{*} \\
(180)\end{array}$ & NS & \multirow{3}{*}{$\begin{array}{c}0.42 \pm 0.06 \\
(12) \\
0.79 \pm 0.06 \\
(14) \\
0.64 \pm 0.05 \\
(7)\end{array}$} & \\
\hline Migraine & - & - & $1.40 \pm 0.26$ & NS & & $<0.001$ \\
\hline Migraine & + & - & $\begin{array}{c}1.06 \pm 0.20 \\
(12)\end{array}$ & NS & & $<0.05$ \\
\hline
\end{tabular}


Analgesics, however, did not affect the 5-HT induced aggregation (Table 6).

With reference to the patients on ergotamine, those on a small dose had, on average, previously had a headache 4.5 days before and eight of 17 patients did not usually take ergotamine, even for attacks. The patients on a large dose had previously had a headache $2 \cdot 25$ days before (average) and all 12 patients had last taken ergotamine within one to two days.

TABLE 5

EFFECT OF ERGOTAMINE ON 5-HT INDUCED AGGREGATION OF PLATELETS FROM MIGRAINOUS SUBJECTS, WITH AND WITHOUT HEADACHE

\begin{tabular}{|c|c|c|c|c|}
\hline Subjects & $\begin{array}{l}\text { Head- } \\
\text { ache }\end{array}$ & Ergotamine & $\begin{array}{c}R \\
(\mathrm{~cm} / \mathrm{min}) \\
\pm S E M\end{array}$ & $\begin{array}{c}P \\
\text { (measured against } \\
\text { migraine, no head- } \\
\text { ache, no ergo- } \\
\text { tamine group) }\end{array}$ \\
\hline Control & - & - & $\begin{array}{c}1 \cdot 21 \pm 0.08^{*} \\
(180)\end{array}$ & NS \\
\hline Migraine & - & - & $\begin{array}{c}1.40 \pm 0.26 \\
(20)\end{array}$ & \\
\hline Migraine & - & $1-2 \times 10^{-3} \mathrm{~g}$ & $\begin{array}{c}0.33 \pm 0.09 \\
(8)\end{array}$ & $<0.001$ \\
\hline Migraine & + & $\begin{array}{l}0.25-0.50 \\
\quad \times 10^{-3} \mathrm{~g}\end{array}$ & $\begin{array}{c}0.60 \pm 0 \cdot 10 \\
(16)\end{array}$ & $<0.01$ \\
\hline Migraine & + & $2-4 \times 10^{-3} \mathrm{~g}$ & $\begin{array}{c}0.32 \pm 0.08 \\
(10)\end{array}$ & $<0.001$ \\
\hline
\end{tabular}

The number of subjects in each group is shown in parentheses. * See Hilton and Cumings (1971).

TABLE 6

EFFECTS OF ANALGESICS ON 5-HT INDUCED AGGREGATION OF PLATELETS FROM MIGRAINOUS SUBJECTS, WITH AND WITHOUT HEADACHE

\begin{tabular}{lcccc}
\hline Subiects & $\begin{array}{c}\text { Head- } \\
\text { ache }\end{array}$ & $\begin{array}{c}\text { Anal- } \\
\text { gesics }\end{array}$ & $\begin{array}{c}R \\
(\mathrm{~cm} / \mathrm{min}) \\
\pm S E M\end{array}$ & $\begin{array}{c}P \\
\text { (measured against } \\
\text { migraine, no headache, } \\
\text { no analgesics group) }\end{array}$ \\
\hline Control & - & - & $\begin{array}{c}1 \cdot 21 \pm 0.08 * \\
(180)\end{array}$ & NS \\
Migraine & - & - & $\begin{array}{c}1 \cdot 40 \pm 0.26 \\
(20)\end{array}$ & \\
Migraine & - & + & $\begin{array}{c}1 \cdot 10 \pm 0.23 \\
(12)\end{array}$ & NS \\
Migraine & + & + & $\begin{array}{c}1 \cdot 23 \pm 0.27 \\
(13)\end{array}$ & NS \\
& & & &
\end{tabular}

The number of subjects in each group is shown in parentheses. * See Hilton and Cumings (1971).

\section{DISCUSSION}

Blood 5-HT levels fell during the migraine $\stackrel{D}{c}$ attack of headache (Table 2) in patients who had not taken drugs and most patients who had taken $\stackrel{\infty}{\subseteq}$ ergotamine, but remained normal in patients who had taken analgesics. It is generally agreed 0 following the studies of Hardisty and Stacey (1955) that the platelets contain virtually all of the blood 5-HT; therefore from the experiments? reported here it can be assumed that it was the $\overrightarrow{\vec{c}}$ platelet 5-HT that was responsible for the changes found, both in patients not on drugs and those on ergotamine.

The aggregation responses of the group not on $\frac{\widehat{\Phi}}{\varnothing}$

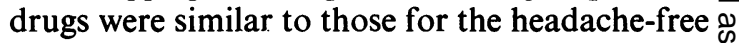
patients and had not been modified by the fall in $\overrightarrow{0}$ 5-HT or the reuptake of 5-HT into the platelet. These results support work already published $\vec{\omega}$ (Hilton and Cumings, 1971) and confirm that a permanent difference exists in the behaviour of platelets from migrainous subjects. Platelets of from migraine sufferers more readily aggregate $\rightarrow$ with 5-HT after one minute's pre-incubation with 5-HT, than do platelets from contro which implies that platelet uptake sites les; readily accept $5-\mathrm{HT}$, or retain it, than do tho of control subjects.

In the migrainous patients both with and without headache ergotamine ingestion inhibit the aggregation response. The relief of migrain cannot be directly due to this because patients without headache and without drugs do not have a low response. Cumings and Hilton (1971) have shown that ergotamine pre-incubation of control platelets inhibited the subsequent aggregation response of the platelets to 5-HT and they $\stackrel{2}{\overrightarrow{7}}$ have suggested that the action of ergotamine on $\frac{0}{3}$ platelet sites may be paralleled at neuronal and vascular sites, which may contribute to the relief of migraine. Michal (1969) considers that platelet 5-HT receptors resemble the D-receptors for 5-HT which are blocked by dibenzyline, dihydroergotamine, and LSD and are located on the smooth muscle of the intestine.

Lingjaerde (1970) has reported that ergotamine inhibits 5-HT uptake by human platelets in vitro 옹 by a non-competitive mechanism. However, he $\frac{D}{0}$ used concentrations of ergotamine which are too high to be physiological and no confirmation of $\widetilde{N}$ his results was found by Cumings and Hilton $N$ 
(1971). Nor is it likely that a drug which inhibits 5-HT uptake in vivo would ameliorate a migraine attack in which 5-HT levels fall.

Analgesics maintained the blood 5-HT level of patients with headache (Table 2) but did not affect the platelet aggregation responses to 5-HT. Aspirin, which is contained in many of the analgesics taken, is known to inhibit the release of 5-HT from the platelets of control subjects (Zücker and Peterson, 1968) and its usefulness in migraine may be due to this effect. The mechanism by which it inhibits 5-HT release cannot be due to its occupying 5-HT uptake sites, since the aggregation response is not affected. It may, however, be due to the inhibition of ADP release from platelets (Doery, Hirsh, and De Gruchy, 1969) which has been observed as the inhibition of the second stage of platelet aggregation after the addition of ADP (Zücker and Peterson, 1968), adrenaline (O'Brien, 1968) and collagen (Ball, Brereton, Fulwood, Ireland, and Yates, 1970) or the effect may be due to a shift of adenine nucleotides from ADP and ATP (Davies, Hughes, and Tonks, 1969), since the content of 5-HT in the platelets is proportional to the ATP present (Born, Ingram, and Stacey, 1957). Badawy and Smith (1971) have recently shown that salicylate inhibits the action of rat liver tryptophan pyrrolase which would divert the metabolism of tryptophan from the kynurenine pathway to the 5-HT pathway. They have also suggested that salicylate can release tryptophan from its binding sites on circulating albumin (and other proteins) which would also tend to raise 5-HT levels.

We are grateful to Dr. Marcia Wilkinson and Dr. K. J. Zilkha for allowing us to investigate patients in their care. One of us (B.P.H.) is grateful for support from the Migraine Trust. Thanks are due to the Medical Illustration Department of the Institute of Neurology for the illustration.

\section{REFERENCES}

Ashcroft, G. W., Crawford, T. B. B., Binns, J. K., and MacDougall, E. J. (1964). Estimation of 5-hydroxytryptamine in human blood. Clinica Chimica Acta, 9, 364-369.

Badawy, A. A.-B., and Smith, M. J. H. (1971). The effects of salicylate on the activity of rat liver tryptophan pyrrolase in vitro and in vivo. Biochemical Journal, 123, 171-174.

Ball, G., Brereton, G. G., Fulwood, M., Ireland, D. M., and Yates, P. (1970). Effect of prostaglandin E1 alone and in combination with theophylline or aspirin on collageninduced platelet aggregation and on platelet nucleotides including adenosine $3^{\prime}: 5^{\prime}$-cyclic monophosphate. Biochemical Journal, 120, 709-718.

Baumgartner, H. R., and Born, G. V. R. (1968). Effects of 5-hydroxytryptamine on platelet aggregation. Nature, 218 , 137-141.

Born, G. V. R., Ingram, G. I. C., and Stacey, R. S. (1957). The proportionality between the amounts of 5-hydroxytryptamine and adenosine triphosphate in blood platelets. Journal of Physiology, 135, 63P-65P.

Cumings, J. N., and Hilton, B. P. (1971). Effects of methysergide on platelets incubated with reserpine. British Journal of Pharmacology, 42, 611-619.

Curran, D. A., Hinterberger, H., and Lance, J. W. (1965). Total plasma serotonin, 5-hydroxyindoleacetic acid and $p$-hydroxy- $m$-methoxymandelic acid excretion in normal and migrainous subjects. Brain, 88, 997-1008.

Davies, D. T. P., Hughes, A., and Tonks, R. S. (1969). The influence of salicylate on platelets and whole blood adenine nucleotides. British Journal of Pharmacology, 36, 437-447.

Doery, J. C. G., Hirsh, J., and De Gruchy, G. C. (1969). Aspirin: its effect on platelet glycolysis and release of adenosine diphosphate. Science, 165, 65-67.

Hardisty, R. M., and Stacey, R. S. (1955). 5-Hydroxytryptamine in normal human platelets. Journal of Physiology, 130, 711-720.

Hilton, B. P., and Cumings, J. N. (1971). An assessment of platelet aggregation induced by 5-hydroxytryptamine. Journal of Clinical Pathology, 24, 250-258.

Lingjaerde, O., Jr. (1970). Effect of ergotamine and dihydroergotamine on uptake of 5-hydroxytryptamine in blood platelets. European Journal of Pharmacology, 13, 76-82.

Michal, F. (1969). D-receptor for serotonin on blood platelets. Nature, 221, 1253-1254.

O'Brien, J. R. (1968). Aspirin and platelet aggregation. Lancet, 1, 204-205.

Zücker, M. B., and Peterson, J. (1968). Inhibition of adenosine diphosphate-induced secondary aggregation and other platelet functions by acetylsalicylic acid ingestion. Proceedings of the Society for Experimental Biology and Medicine, 127, 547-551. 